\title{
Variations in origin, course and distribution of lingual nerve: A cadaveric study
}

\author{
Premakumari C R ${ }^{1}$, Dnyaneshwar ${ }^{2, *}$ \\ ${ }^{\mathbf{1}}$ Assistant Professor, Dept. of Anatomy, Karwar Institute of Medical Sciences, Karwar, Karnataka, ${ }^{\mathbf{2}}$ Associate Professor, Dept. of \\ Anatomy, Koppal Institute of Medical Sciences, Koppal, Karnataka, India
}

*Corresponding Author:

Email: drdnyan83@gmail.com

Received: $3^{\text {rd }}$ February, 2018

Accepted: $12^{\text {th }}$ April, 2018

\begin{abstract}
Introduction: The lingual nerve is a branch from posterior trunk of mandibular nerve and is sensory to the tongue, lingual gingivae and conveys postganglionic secretomotor fibres to submandibular, sublingual and anterior lingual glands. The nerve is joined by the chorda tympani branch of the facial nerve, and often by a branch of the inferior alveolar nerve. Submandibular ganglion is connected to the lingual by anterior and posterior filaments. ${ }^{1}$ Communications between Lingual nerve (LN) and Mylohyoid nerve (MHN) may be the possible explanation for the functional recovery of LN when its get injured during third molar extraction. ${ }^{4}$

Materials and Methods: A study was carried out in twenty embalmed cadavers and forty lingual nerves were studied by standard dissection method.

Results: out of forty lingual nerves studied one lingual nerve was found to be arising from two roots. Anterior (AR) \& posterior (PR). Mylohyoid nerve was found to be connected with the submandibular ganglion by two roots (anterior and posterior) and later was found to join the lingual nerve. A CB from $\mathrm{LN}$ joined posterior root.

Discussion: Kim et al. described the communication between MHN \& LN in $12.5 \%$ of 32 heads and first mentioned that this communication could provide another route of sensory transmission, being a possible cause of incomplete anaesthesia during dental practice. ${ }^{6}$

Conclusion: Our study showed multiple variations in one specimen which included variation in its origin (partly taking origin from anterior division of MN along with posterior division), communication with MHN, MHN was connected to submandibular ganglion by two roots. The incidences of all these variations in our study were $2.5 \%$.
\end{abstract}

Keywords: Lingual nerve, Inferior alveolar nerve, Mylohyoid nerve, Submandibular ganglion.

\section{Introduction}

The lingual nerve is a branch from posterior trunk of mandibular nerve and is sensory to the mucosa of anterior two thirds of the tongue, floor of the mouth, and mandibular lingual gingivae. The lingual nerve is the topographical relation of submandibular ganglion conveying postganglionic parasympathetic secretomotor fibers to submandibular, sublingual and anterior lingual glands.

The lingual nerve arises from the posterior trunk of the mandibular nerve and at first runs beneath lateral Pterygoid where it is joined by the chorda tympani branch of the facial nerve, and often by a branch of the inferior alveolar nerve. The nerve then runs close to the medial surface of mandibular ramus where it lies anterior and slightly deeper than inferior alveolar nerve. It next passes below the superior constrictor and reaches opposite the third molar tooth where it is only covered by gingival mucoperiosteum. The nerve then passes downwards and forwards on the deep surface of mylohyoid nerve and over the hyoglossus muscle. Then it passes below the mandibular duct, which crosses from medial to lateral and curves upwards, forwards and medially to enter the tongue by medial and lateral branches. Submandibular ganglion is connected to the lingual by several filaments. The posterior filament is motor conveying from superior salivatory nucleus via facial, chorada tympani and lingual nerves to the ganglion. Five to six postganglionic branches from the ganglion supply submandibular gland and through the anterior filaments supply sublingual and anterior lingual glands. ${ }^{1}$

The inferior alveolar nerve, a branch from posterior division of mandibular nerve gives mylohyoid nerve that leaves inferior alveolar at mandibular foramen. It then pierces the spinomandibular ligament and lies in mylohyoid groove accompanied by similar nerves, the mylohyoid nerve then runs forward over the superficial surface of mylohyoid supplying it at the anterior belly of diagastric. The myhyoid nerve forms only motor distribution from posterior division of mandibular nerve. $^{2}$

Because of very close relationship of $\mathrm{LN}$ with the third molar tooth makes it Susceptible to injury during third molar too the extraction. ${ }^{17}$ Communications between Lingual nerve (LN) and Mylohyoid nerve (MHN) may be the possible explanation for the functional recovery of $\mathrm{LN}$ when its get injured during third molar extraction. ${ }^{4}$

Communications between Lingual nerve (LN) and Mylohyoid nerve (MHN) forms importance in oral and maxillofacial surgeries and periodontal procedures. This communication may be the possible explanation for the inefficiency of mandibular anaesthesia. ${ }^{4}$ 
Communications between Lingual nerve (LN) and Mylohyoid nerve (MHN) also explains that Mylohyoid nerve could be considered as a mixed nerve which transmits through the anastomotic branch the sensitive, postganglionic vegetative fibres to the $\mathrm{LN} .{ }^{3}$

\section{Materials and Methods}

A study was carried out in twenty embalmed cadavers and forty lingual nerves were studied with respect to their origin, course and distribution. The study was carried out by standard dissection method and dissection instruments. The Study was carried out in Karwar Institute of Medical Sciences.

\section{Observations and Results}

In the present study out of forty lingual nerves studied, thirty nine specimens showed normal origin, course and distribution.

One of the lingual nerves showed the following variations. The lingual nerve was found to be arising from two roots. Anterior (AR) \& posterior (PR). AR was arising from anterior division of Mandibular Nerve $(\mathrm{MN})$ \& PR was arising from inferior alveolar nerve at the same point where Chorda tympani was joining posterior aspect of Lingual nerve as usual. The lingual nerve thereafter was running downwards, anterior and deep to inferior alveolar nerve. Mylohyoid nerve was found to be connected with the submandibular ganglion by two roots (anterior and posterior) and thus supplying submandibular gland. Later the mylohyoid nerve was found to join the lingual nerve and supplied mylohyoid muscle through lingual nerve. The lingual nerve was giving a communicating branch that was found to join the posterior root of the mylohyoid nerve. After joining with mylohyoid nerve, it supplied mylohyoid and followed its usual distribution.

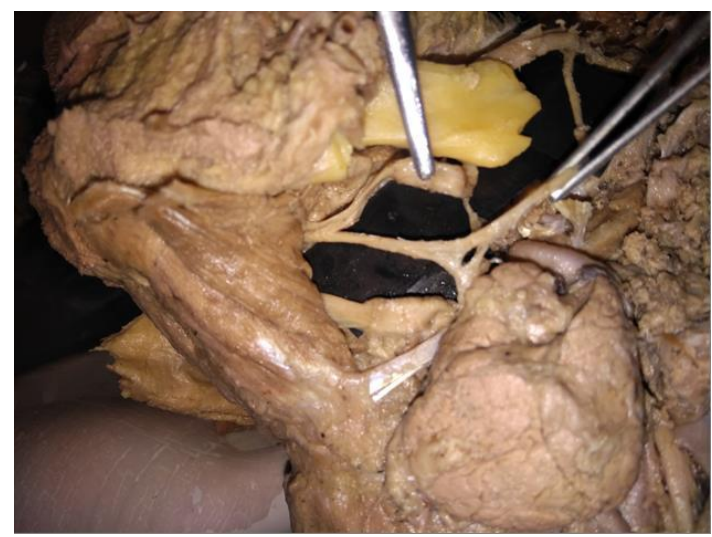

Fig. 1

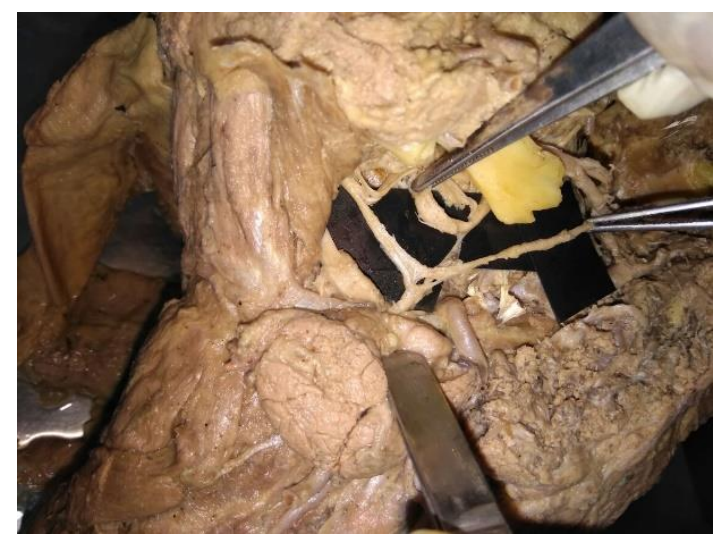

Fig. 2

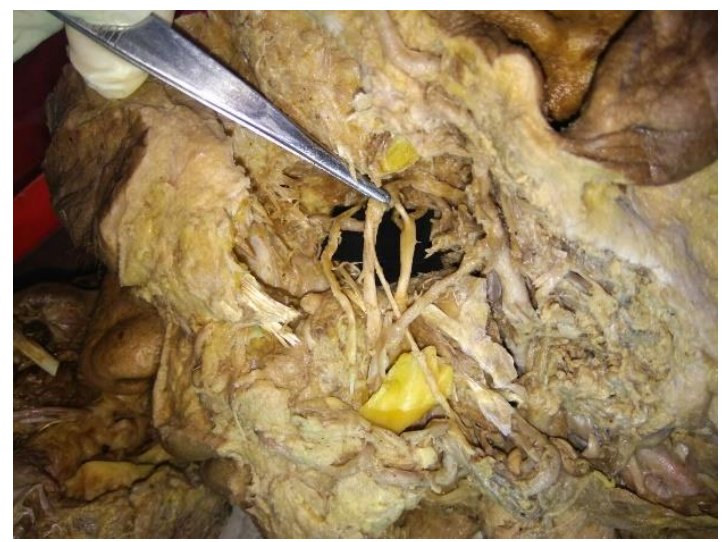

Fig. 3

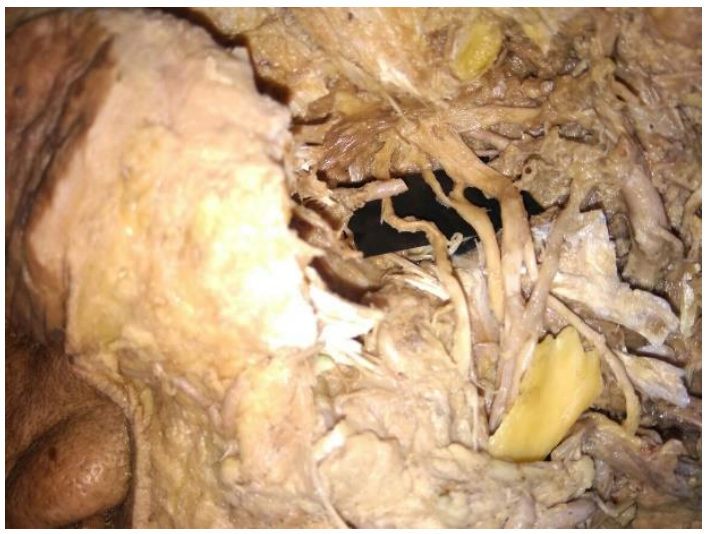

Fig. 4

\section{Discussion}

A study done by Racs L \& Maros T in 24 human heads from embalmed cadavers found the following variations; in $33.3 \%$, one of the terminal branches of $\mathrm{MN}$ anastomoses with $\mathrm{LN}$ in lateral sucus of tongue, in $25 \%$, connection bridges were found between LN \& IAN. In $4.1 \%$ origin of $\mathrm{LN}$ formed by two roots. ${ }^{3}$

Potu BK reported unusually thick MHN arising from mandibular nerve (MN) and found to be giving a communicating branch that was joining lingual nerve. The variation was found out of 15 cadavers during routine dissection. ${ }^{4}$ Fazan VP also mentions the similar 
variation of communication between MHN\&LN in 55 year old male cadaver. ${ }^{5}$

Kim et al. described the communication between MHN \& LN in $12.5 \%$ of 32 heads and first mentioned that this communication could provide another route of sensory transmission, being a possible cause of incomplete anaesthesia during dental practice. ${ }^{6}$

Daimi SR reported a variation in 65 year old male cadaver in which $\mathrm{LN}$ was formed by two roots; anterior $(\mathrm{AR})$ and posterior (PR). PR originated directly from MN while AR was a branch from common trunk (CT). $\mathrm{CT}$ originated from $\mathrm{MN}$ directed downward and divided into two branches; one as $\mathrm{AR}$ of $\mathrm{LN}$ and another as Inferior alveolar nerve (IAN). ${ }^{7}$ Unusual communication between LN\&MHN over hyoglossus has been reported by Thomas et al. ${ }^{8}$

Kaur HS et al. has reported an abnormal bilateral communication between the MHN \& LN in middle aged male cadaver on the right side the communication was beyond the level of mandibular foramen close to intermediate tendon of digastric and on the left side the communication was at the level of mandibular foramen before intermediate tendon of digastric. ${ }^{9}$ similar variation has been mentioned by Sinha $P$ and communication was at the junction of anterior belly and intermediate tendon of digastric. ${ }^{10}$

Iamsaard S conducted a study of 102 samples of mandibular nerves in 51 sections of head \& neck in Thai population found a very rare and unusual communication between posterior division of TV$3(\mathrm{MN})$ and $\mathrm{LN}$ above its junction with chorda tymphani in a 71 year old woman. ${ }^{11}$ Similar variation was found by Shobhakumari in amle cadaver which also showed communication between Auriculotemporal nerve and IAN. ${ }^{12}$

A study conducted by Thotakura $\mathrm{B}$ in 36 specimens showed MHN-LN communications in 2 speicmens, bilateral in one, communicating branch thicker than MHN, arising from MHN at the lower border of lateral Pterygoid. ${ }^{13}$ Exclusive study on mandibular nerve conducted by Siessare $\mathrm{S}$ in 20 human heads showed $20 \%$ variations involving masseter, temporal, ATN \& LN. ${ }^{14}$

A study of 13 cadavers with respect to lingual nerve, found in 11 specimens- A thick gingival branch which supplied lingual periosteum, gingiva, mucosa that overlying medial alveolar process. ${ }^{15}$ Clinical problems in obtaining complete anaesthesia of IALexplains MHN receiving secondary innervations by $\mathrm{LN}$ or other branches of posterior division of MN. ${ }^{16}$

Frommer gives an explanation of possible role of MHN in posterior tooth sensation. ${ }^{17}$ Adjei reported two cases of damage to MHN following excision of submandibular gland followed by analgesia of chin. ${ }^{19}$ Keven $\mathrm{T}$ also mentions communication between IAN\&LN in left side. ${ }^{20}$

\section{Conclusion}

Variations of lingual nerve mentioned in literatures include its communication with mylohyoid nerve and with inferior alveolar nerves, variation in its origin in which $\mathrm{LN}$ arising from different roots of $\mathrm{MN}$ and additional branches of lingual nerve. Our study showed multiple variations in one specimen which included variation in its origin (partly taking origin from anterior division of $\mathrm{MN}$ along with posterior division), communication with MHN, communication with MHN, MHN was connected to submandibular ganglion by two roots- anterior \&posterior. A communicating branch from $L N$ joined posterior root.

Most of the literatures mention unusual thickness of MHN and then MHN giving a communicating branch that join with $\mathrm{LN}$ at different levels of digastric muscle. No literature so far mentions the connection of submandibular ganglion (SG) with the MHN. In our case the SG was suspended by MHN and LN was found to give a communicating branch which was joining the posterior root. Our study showed unique variation of lingual nerve in its communication with MHN in which SG was found to be suspended by MHN instead of lingual nerve.

The variations found in our study may conclude that MHN could have sensory distribution along with motor fibres and also could carry secretomotor fibers to Submandibular, sublingual and anterior lingual glands via its communications with $\mathrm{LN}$. The above variation may also give explanation of inadequate mandibular anaesthesia and may also explain the functional recovery of $\mathrm{LN}$ when it get injured frequently in molar extraction.

\section{List of Abbreviations}

MN- Mandibular Nerve

LN- Lingual nerve

IAN-Inferior alveolar nerve

MHN-Mylohyoid nerve

ATN-auriculotemporal nerve

TV-trigeminal nerve

SG-Submandibular ganglion

ChoR.T- Chorda tympani Nerve

\section{References}

1. Standring S ed. Gray's anatomy. The anatomical basis of clinical practice. 41 st ed. London: Churchill Livingstone Elsevier; 2016:551,514,528.

2. Sinnatamby C S. Last's Anatomy-regional and applied.11th ed. Churchill Livingstone Elsevier;2006:379.

3. Racz, V. L. \& Maros, T. The anatomic variants of the lingual nerve in human. Anat. Anz., 1998;149(1):64-71.

4. Potu BK, D'Silva SS, Thejodhar P, Jattanna NC. An unusual communication between the mylohyoid and lingual nerves in man: Its significance in lingual nerve injury. Indian J Dent Res. 2010;21(1):141-2.

5. Fazan VP, Rodrigues Filho OA, Matamala F. Communication between the mylohyoid and lingual 
nerves: Clinical implications. Int J Morphol. 2007;25(3):561-4.

6. Kim, S.Y.; Hu, K.S.; Chung, I. H.; Lee, E.W. \& Kim, HJ. Topographic anatomy of the lingual nerve and variations in communication pattern of the mandibular nerve branches. Surg Radiol Anat. 2004;26:(2)128-35.

7. Daimi S R, Siddiqui A U, Vyas V R, Sheikh S. Unique presentation of maxillary artery, Lingual nerve, and inferior alveolar complex. Int J Appl Basic Med Res. 2011 Jul-Dec;1(2):125-126.

8. Thomas et al. An anomalous communication between nerve to mylohyoid and the lingual nerves and its clinical implications- A case report. Asia Pacific Journal of Research, 1 (XXV). pp. 16-18.

9. Kaur H S, Upasana, Bajwa SJ S, kalian G S, Singh M. Bilateral communication between the mylohyoid and lingual nerves: clinical implications AMHS. Jul-Dec 2014:2(2):217-219.

10. Sinha P, Tamang B K, Sarda R K. Communication between Mylohyoid and Lingual Nerve: An Anatomical Variation. Journal of clinical Diagnostic and research. 2014:8(4):1-2.

11. Iamsaards S, Singshorn J, Boonruangsri P. An unusual communication between the trunk of the mandibular nerve and the lingual nerve in a female cadaver. Acta Medica Academica 2015;44(2):201-202.

12. Kumari S, Prasad A, Subratanag, Britto J, Rita Kumari R. Unusual bilateral communication between the various branches of posterior division of mandibular nerve: its clinical significance. Journal of Dental and Medical Science. 2015:14(8):36-39.

13. Thotakura B, Rajendran SS, Gnanasundaram V, Subramaniam A. Variations in the posterior division branches of the mandibular nerve in human cadavers. Singapore Med J. 2013;54(3):149-51.

14. Siéssere S, Hallak Regalo SC, Semprini M, et al. Anatomical variations of the mandibular nerve and its branches correlated to clinical situations. Minerva Stomatol. 2009;58(5):209-15.

15. Kocabiyik N, Varol A, Sencimen M, Ozan H. An unnamed branch of the lingual nerve: gingival branch. $\mathrm{Br}$ J Oral Maxillofac Surg. 47(3):214-217. https://doi.org/10.1016/j.bjoms.2008.07.197

16. Pai MM, Swamy RS, Prabhu LV. A variation in the morphology of the inferior alveolar nerve with potential clinical significance. Biomed Int. 2010;1:93-5.

17. Frommer, J.; Mele, F. A. \& Monroe, C.W. The possible role of the mylohyoid nerve in mandibular posterior tooth sensation. J Am Dent Assoc. 1972;85(1):113-7,

18. Behnia H.; Kheradvar, A. \& Shahrokhi, M. An anatomic study of the lingual nerve in the third molar region. $J$ Oral Maxillofac Surg. 2000;58(6):649-51.

19. Adjei, S. S. \& Hammersley, N. Mylohyoid nerve damage due to excision of the submandibular salivary gland. Br J Oral Maxillofac Surg. 1989;27(3):209-11.

20. Wolf KT, Brokaw EJ, Bell A, Joy A. Variant inferior alveolar nerve and implications for local anaesthesia. Anaesth Prog. 2016; 63(2):84-90.

How to cite this article: Premakumari CR, Dnyaneshwar. Variations in origin, course and distribution of lingual nerve: A cadaveric study. Ind J Clin Anat Physiol. 2018;5(3):357360. 